\title{
ERRATUM
}

\section{Erratum zu: Mensch-Computer-Interaktion als zentrales Gebiet der Informatik - Bestandsaufnahme, Trends und Herausforderungen}

\author{
Michael Koch ${ }^{1}$ Jürgen Ziegler · Christian Reuter · Thomas Schlegel · Michael Prilla
}

Online publiziert: 23. Juli 2021

(c) Der/die Autor(en) 2021

\section{Erratum zu:}

\section{Informatik Spektrum 2020}

https://doi.org/10.1007/s00287-020-01299-8

Der Artikel „Mensch-Computer-Interaktion als zentrales Gebiet der Informatik - Bestandsaufnahme, Trends und Herausforderungen“" von Michael Koch, Jürgen Ziegler, Christian Reuter, Thomas Schlegel und Michael Prilla wurde ursprünglich Online First ohne „Open Access“ auf der Internetplattform des Verlags publiziert. Nach der Veröffentlichung in Bd. 43 Heft 6 S. 381-387 hatten sich die Autoren für eine „Open Access"-Veröffentlichung entschieden. Das Urheberrecht des Artikels wurde deshalb in (C) Der/die Autor(en) 2020 geändert.

Die Online-Version des Originalartikels ist unter https://doi.org/ 10.1007/s00287-020-01299-8 zu finden.

Michael Koch

michael.koch@unibw.de

1 Fakultät für Informatik, Universität der Bundeswehr München, München, Deutschland
Funding Open Access funding enabled and organized by Projekt DEAL.

Open Access Dieser Artikel wird unter der Creative Commons Namensnennung 4.0 International Lizenz veröffentlicht, welche die Nutzung, Vervielfältigung, Bearbeitung, Verbreitung und Wiedergabe in jeglichem Medium und Format erlaubt, sofern Sie den/die ursprünglichen Autor(en) und die Quelle ordnungsgemäß nennen, einen Link zur Creative Commons Lizenz beifügen und angeben, ob Änderungen vorgenommen wurden.

Die in diesem Artikel enthaltenen Bilder und sonstiges Drittmaterial unterliegen ebenfalls der genannten Creative Commons Lizenz, sofern sich aus der Abbildungslegende nichts anderes ergibt. Sofern das betreffende Material nicht unter der genannten Creative Commons Lizenz steht und die betreffende Handlung nicht nach gesetzlichen Vorschriften erlaubt ist, ist für die oben aufgeführten Weiterverwendungen des Materials die Einwilligung des jeweiligen Rechteinhabers einzuholen.

Weitere Details zur Lizenz entnehmen Sie bitte der Lizenzinformation auf http://creativecommons.org/licenses/by/4.0/deed.de. 